\title{
Preparation of Nano Tourmaline Surface Treatment Agent and Its Application on Functional Wall fabrics
}

\author{
Fangxing LAN ${ }^{1, \text { a }}$, Bangkui MA ${ }^{2, \mathrm{~b}}$, Wei $\mathrm{LI}^{1,3, \mathrm{c}}$ and Xiaoyun $\mathrm{LIU}^{1, \mathrm{~d}}$ \\ ${ }^{1}$ Key Laboratory for Specially Functional Polymeric Materials and Related Technology of \\ the Ministry of Education, East China University of Science and Technology, Shanghai \\ 200237, China \\ ${ }^{2}$ Jiangsu Tengsheng textile Industry Group, Shuyang 223600, China \\ ${ }^{3}$ Chongqing Polycomp International Corp, Chongqing 400084, China \\ alan19910220@126.com, ${ }^{\mathrm{b}}$ mbk_2005@163.com, ${ }^{\mathrm{c}}$ cpiclw@cpicfiber.com, \\ dliuxiaoyun@ecust.edu.cn
}

\begin{abstract}
In this paper, a kind of surface treatment agent and its application on the functional wall fabrics that can produce negative ion was reported. This surface treatment agent was prepared by using nano tourmaline powder dispersion with water as solvent produced by sand milling. The parameters of sand milling process, as well as powder diameter and its distribution, and the negative ion releasing behavior of the functional wall fabrics were discussed. The results showed that nano tourmaline had good dispersity stability with the number average diameter (d50) achieved $190 \mathrm{~nm}$ and the polydispersity index reached to 0.220 . The treated wall fabrics showed good performance in high adsorption with nano powder and high negative ions releasing ability. The negative ions releasing amount changes depending on the different surface treatment process of tourmaline dispersion and three-proofing agent. This facility technics could be widely used as industrial application.

Keywords: Tourmaline, nanomaterial, negative ion, wall fabrics, functional textile
\end{abstract}

\section{Introduction}

Tourmaline had been widely researched and applied in air and water purification, fabrics, coating and cosmetics due to its functional ability such as releasing negative ions $[1,2]$. The mineral powder were studied and used for fiber production with electrostatic spinning $[3,4]$. This method can rapidly adsorb nano powder inside and surface of nanofiber, but decreased the interface catalysis due to the untouch with inside nano powder. Only few surface of fabric can contact and interact with water around air [5]. An reasonable method is using surface 
treatment as textile finishing agent. This facility method can reduce cost about materials and technics [6].

Wall fabrics are rising up increasing interest by reason of its diversity designed, green, water /oil proofing, soft and comfortable. The commercial wall fabrics is very fashionable, but the functional product is very less due to the commercial finishing agent cannot be compatible with each other. In this paper, we reported the method to obtain nano tourmaline water dispersion surface treatment agent and its application on functional wall fabrics.

\section{Experiment}

\subsection{Materials}

Tourmaline powder was purchased from Shanxi mineral Co. Ltd and used as received. Wall fabrics were purchased from Jiangsu Tengsheng textile Industry Group. Grind auxiliary agent (agent GA) was purchased from BYK Co. Ltd. Three proofing agent (agent TP) was purchased from Shanghai NaNo Colloid Co. Ltd; Other materials was purchased from commercial suppliers and used without further purification.

\subsection{Test}

Using Laser Grain Size Analyzer(Mastersizer 2000, Malvern Co.Ltd) measured the size distribution of tourmaline particles; Observing the nano tourmaline particles dispersion and the wall fabrics fiber surface morphological details by Field-Emission Scanning Electron Microscope (Ultra 55, Germany Zeiss Co.Ltd) with an acceleration voltage of 5KV, the sample were coated with gold metal layer to provide proper surface condition; The method of the negative ions amount test were based on the People's Republic of China Building Material Industry Standard JC/T 1016-2006 "Testing on negative ion concentration of materials" to control the environmental conditions with temperature at $23 \pm 1{ }^{\circ} \mathrm{C}$ and relative humidity at 50 $\pm 5 \%$ using Air ions counter(COM-3600F, Japanese com-system Co.Ltd)

\section{Results and Discussion}

\subsection{Preparation of Nano Tourmaline Dispersion}

Tourmaline powder was mixed with agent GA and water (Tourmaline/ agent GA/ water wt $\%=10 / 3 / 87$ ) using mechanical agitation to make the initial dispersion (dispersion NT). The dispersion was then grand milled with the $0.3 \mathrm{~mm}$ zirconia for $3 \mathrm{~h}$ and cooled to room temperature continuous. A well-dispersity and stable emulsion was obtained.

The relationship of particle size and process time was showed in Fig. 1. When milling time is up to $90 \mathrm{~min}$, the particle average diameter (d50) decreased to $240 \mathrm{~nm}$ and finally to $190 \mathrm{~nm}$. The polydispersity index (P.D.I) was reached to 0.220 , which means the uniform particle was obtained. Fig. 2 showed the final particle diameter distribution. The SEM morphology of particle was showed in Fig. 3. The photograph indicated that exist the acicular structure. 


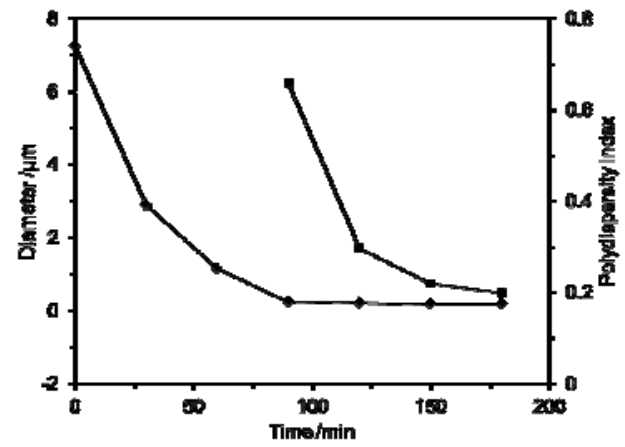

Fig. 1 The relationship between milling time, diameter and polydispersity index

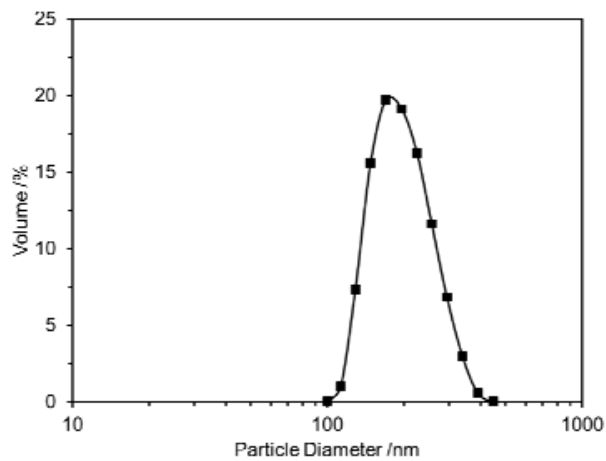

Fig. 2 The Particle diameter distribution with milling time of $180 \mathrm{~min}$

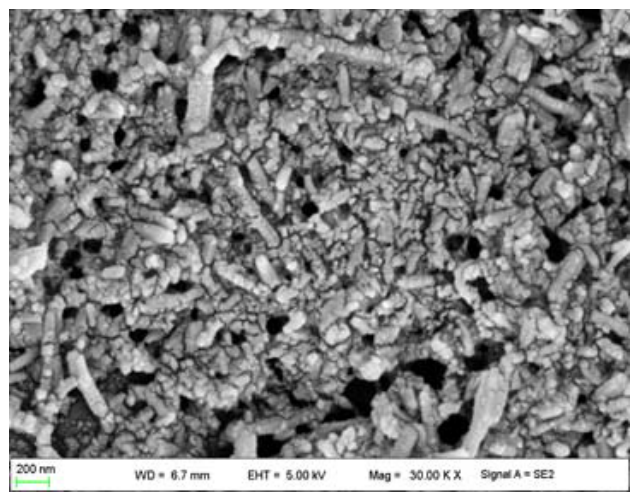

Fig. 3 The SEM of nano tourmaline particles with milling time of $180 \mathrm{~min}$

\subsection{Preparation of Functional Wall Fabrics}

$10 \mathrm{~g}$ the dispersion NT and $3 \mathrm{~g}$ agent TP was mixed and added $87 \mathrm{~g}$ deionized water as solution to prepare surface treatment agent A1 (tourmaline content $1 \mathrm{wt} \%$ ). Then the surface treatment agent was used to dipping wall fabrics for $30 \mathrm{~s}$ and then dried for 5 in $160^{\circ} \mathrm{C}$. The content formulation of other surface treatment were showed in Table 1 and were prepared with the same process. The comparing series were treated the wall fabrics with agent $\mathrm{C}$ after treating by agent B1, B2, B3 and numbered by B1C, B2C, B3C. The samples having same treatment process with difference nano tourmaline content were named as Treated $\mathrm{A}$, Treated B, Treated BC. 

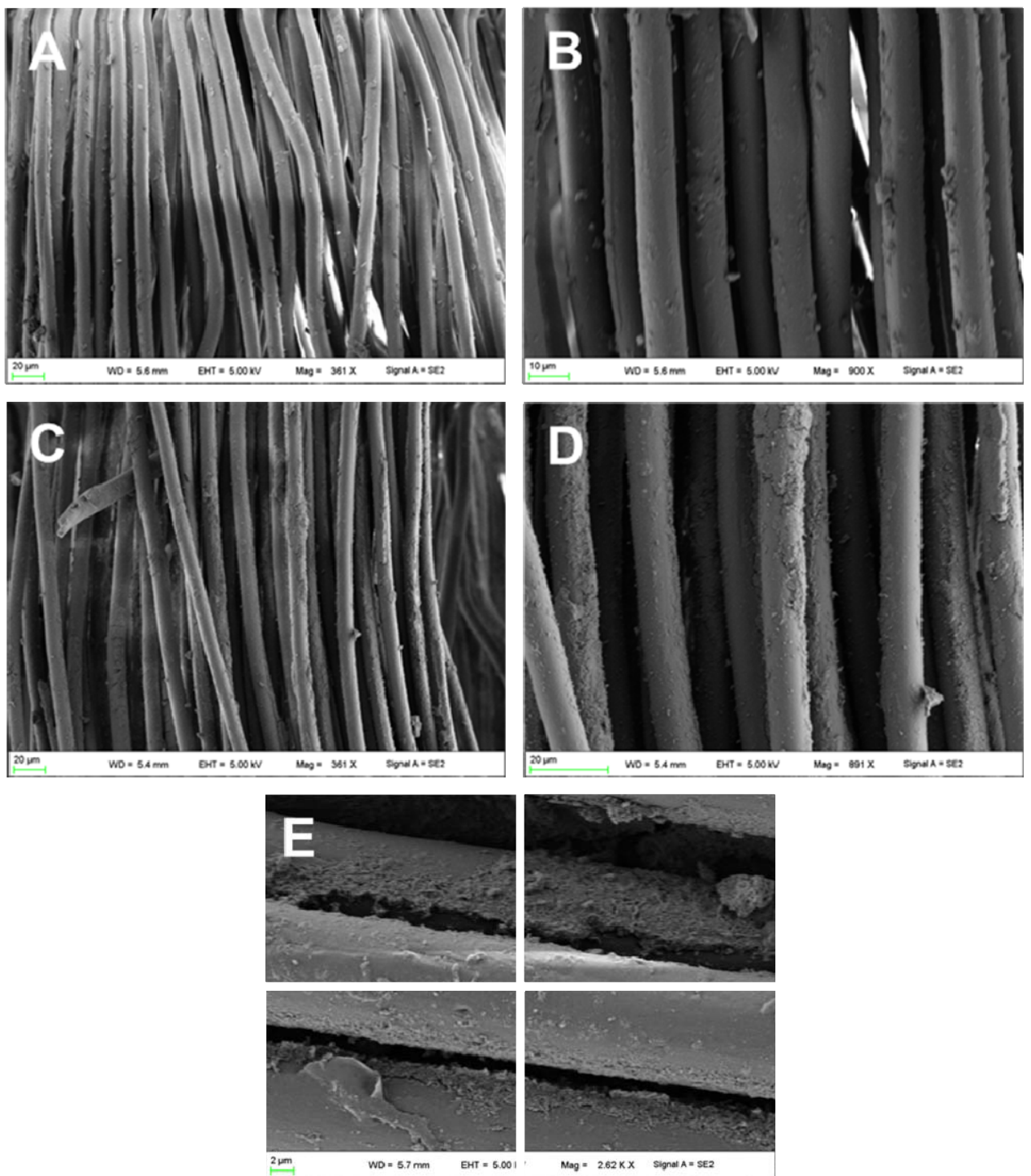

Fig. 4 The SEM for wall fabrics fiber without untreated fiber (A and B) and with treated fiber $(\mathrm{C}, \mathrm{D}$ and $\mathrm{E})$ by nano tourmaline surface treatment agent $\mathrm{B} 3$

Fig. 4 is The SEM photograph for wall fabrics fiber which was untreated and treated by nano tourmaline surface treatment agent B3 with different magnification. As shown in Fig. 4, the untreated fiber behaved almost smooth fiber surface. However, the adding of tourmaline greatly improved the adsorption of particle and behaved unsmooth coating and even dispersion of nano particles on the fiber surface. This illustrated that the fiber showed well interaction with nano tourmaline particles. 
TABLE 1 THE COMPARED SURFACE TREATED AGENT SAMPLE CONTENT

\begin{tabular}{cccc}
\hline NO. & $\begin{array}{c}\text { Dispersion NT } \\
/ \mathrm{g}\end{array}$ & $\begin{array}{c}\text { Agent TP } \\
/ \mathrm{g}\end{array}$ & $\begin{array}{c}\text { Deioned Water } \\
/ \mathrm{g}\end{array}$ \\
\hline A1 & 10 & 3 & 87 \\
A2 & 30 & 3 & 67 \\
A3 & 50 & 3 & 47 \\
B1 & 10 & 0 & 90 \\
B2 & 30 & 0 & 70 \\
B3 & 50 & 0 & 50 \\
C & 0 & 3 & 97 \\
\hline
\end{tabular}

\subsection{Performance of Tourmaline Functional Wall Fabrics}

The aim of nano tourmaline functional wall fabrics was the high releasing negative ions ability. Thus the wall fabrics could have the best air purification performance.

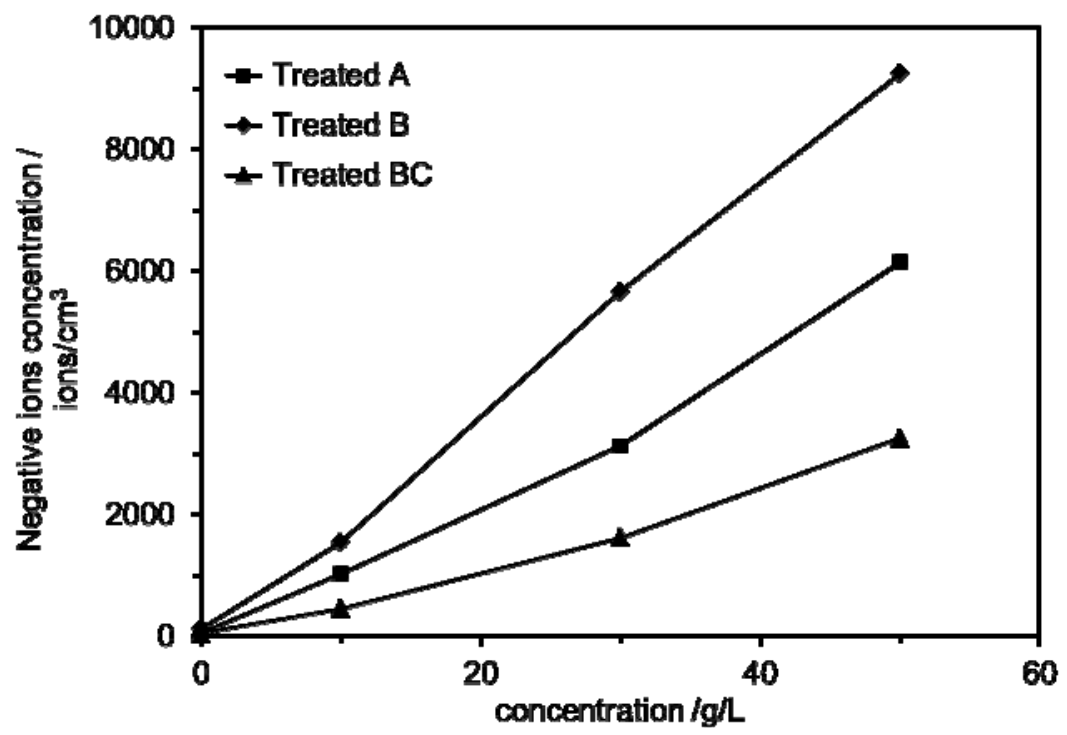

Fig. 5 The relationship between releasing ability and tourmaline content of surface treatment agent

Fig. 5 is the releasing negative ions ability performance of wall fabrics treated by nano tourmaline surface treatment agent with different tourmaline content. As shown in Fig. 5, different treatment process have different negative ions releasing ability. Both of them showed negative ions releasing amount fast increasing by nano tourmaline content. Although the negative ions releasing amount would increasing by increasing nano tourmaline content, the max content of nano tourmaline was limited and lowered than $60 \mathrm{~g} / \mathrm{L}$ since the balance should be considered between the cost, the high hardness of cloth and low gloss of cloth. Treated A and Treated BC compared with Treated B showed lowest negative ions releasing ability since the waterproofing treatment weakened the water molecular interaction with particles surface of the fiber. 
TABLE 2 THREE TREATMENTS COMPARING WITH NEGATIVE IONS RELEASING ABILITY

\begin{tabular}{cccc}
\hline $\begin{array}{c}\text { Tourmanline content } \\
\mathrm{g} / \mathrm{L}\end{array}$ & $\begin{array}{c}\text { Treated A } \\
\text { ions } / \mathrm{cm}^{3}\end{array}$ & $\begin{array}{c}\text { Treated B } \\
\text { ions } / \mathrm{cm}^{3}\end{array}$ & $\begin{array}{c}\text { Treated BC } \\
\text { ions } / \mathrm{cm}^{3}\end{array}$ \\
\hline 0 & 52 & 123 & 51 \\
10 & 1031 & 1543 & 456 \\
30 & 3134 & 5672 & 1621 \\
50 & 6153 & 9253 & 3254 \\
\hline
\end{tabular}

Furthermore, with the same content of nano tourmaline and three-proofing agent showed great difference between Treated A and Treated BC. Treated A behaved great released amount than Treated $\mathrm{BC}$. This strange behavior can been explained by surface particle content. With the Treated BC process particle adsorbed surface almost be covered with the water proofing agent, while Treated A shows crowded neighborhood relationship.

Table 2 is the relationship between negative ions releasing ability and tourmaline content for the three treatment process. All wall fabrics with Treated B process were unwater proofing treatment. Although wall fabrics with Treated B process can reach the max releasing negative ions to 9253 ions $/ \mathrm{cm}^{3}$, waterproofing finishing is the basic and inevitable for wall fabrics application. Therefore, Treated A process is reasonable which the negative ions releasing ability can be up to 6153 ions $/ \mathrm{cm}^{3}$ max.

\section{Conclusion}

Nano tourmaline surface treatment agent (tourmaline content $10 \mathrm{wt} \%$ ) were prepared. The average particle size of tourmaline in the surface treatment agent is $190 \mathrm{~nm}$. The functional wall fabrics treated by this surface treatment agent showed good performance in high adsorption with nano powder and high negative ions releasing ability. The max released amount showed 6153 ions $/ \mathrm{cm}^{3}$ for reasonable treatment process. This facility techniques could be widely used in the as functional textile.

\section{References}

1. J.F. Guan, X.F. Hu, J.Q. Shu, Experimental study on decolorization of acid black wastewater by microporous material of rectorite, Environ. Sci. Technol. 30 (2007) 80-82.

2. F. Li, S. Li, Y. Liu, Tourmaline's function on drinking water purification, Ceram. 6 (2003) 3436-3437.

3. R. Knsslek, J. Fenn, G. Teppcr, The use of AC potential in electrospraying and electrospinning

4. $\quad$ Processes, Polymer. 45 (2004) 2981-2984.

5. Y.M Hu, X. Yang, The surface organic modification of tourmaline powder by span-60 and its composite, Appl. Surf. Sci. 258 (2012) 7540-7545.

6. Y. Wang, J.T. Yeh, T.J. Yue, Surface modification of superfine tourmaline powder with titanate coupling agent, Colloid Polym. Sci. 284 (2006) 1465-1470.

7. X.S Bian, J.Q. Chen, R. Ji, Degradation of Methyl Blue Using Fe-Tourmaline as a Novel Photocatalyst, Molecules. 18 (2013) 1457-1463. 